\title{
The role of glial-neuronal metabolic cooperation in modulating progression of multiple sclerosis and neuropathic pain
}

\author{
Rachel R Robinson1, Alina K Dietz ${ }^{1}$ Asif M. Maroof ${ }^{1}$, Reto Asmis² \& Thomas G Forsthuber*,1 \\ ${ }^{1}$ Department of Biology, University of Texas at San Antonio, TX 78249, USA \\ ${ }^{2}$ Department of Internal Medicine, Wake Forest School of Medicine, Medical Center Boulevard, Winston-Salem, NC 27157, USA \\ *Author for correspondence: Tel.: +1 210458 5760; Fax: +1 210458 5499; thomas.forsthuber@utsa.edu
}

While the etiology of multiple sclerosis (MS) remains unclear, research from the clinic and preclinical models identified the essential role of inflammation and demyelination in the pathogenesis of MS. Current treatments focused on anti-inflammatory processes are effective against acute episodes and relapsingremitting MS, but patients still move on to develop secondary progressive MS. MS progression is associated with activation of microglia and astrocytes, and importantly, metabolic dysfunction leading to neuronal death. Neuronal death also contributes to chronic neuropathic pain. Metabolic support of neurons by glia may play central roles in preventing progression of MS and chronic neuropathic pain. Here, we review mechanisms of metabolic cooperation between glia and neurons and outline future perspectives exploring metabolic support of neurons by glia.

First draft submitted: 2 October 2018; Accepted for publication: 19 November 2018; Published online: 11 January 2019

Keywords: astrocyte $\bullet$ glia $\bullet$ metabolic coupling $\bullet$ microglia $\bullet$ multiple sclerosis $\bullet$ neuron $\bullet$ neuropathic pain $\bullet$ progressive $\bullet$ SPMS $\bullet$ virtual hypoxia

Approximately 149.2 people per 100,000 are affected by multiple sclerosis (MS) in the USA [1]. The most common form of MS is relapsing-remitting MS (RRMS) and it affects about $85 \%$ of patients at initial diagnosis [2]. RRMS is characterized by acute episodes of enhanced disease severity (relapse) followed by periods of remission. After an average of 19 years of diagnosis approximately 60\% of patients with RRMS progress to a second type of MS, secondary progressive MS (SPMS) [2], where patients no longer remit. Primary progressive MS (PPMS) is another, much less frequently observed form of the disease, accounting for approximately $10 \%$ of patients at diagnosis [3]. Patients with PPMS continue to progress after onset and do not experience remissions. Importantly, the progressive forms of disease are not well controlled by current therapies [4].

Inflammatory demyelinating lesions are a hallmark feature of MS. Lesions can be found throughout the CNS in both white and grey matter [5,6]. The histological makeup of lesions can be quite heterogenous, but in general they are characterized by demyelination, immune cell infiltration and reactive gliosis. The etiology of MS is still unclear, but is likely due to the interplay between genetic susceptibility and a predisposing environment. There are documented genetic and environmental factors that increase the risk of development of MS. For example, women are 3.13-times more likely to develop MS than men [1], and the strongest genetic risk factor for developing MS is the HLA-DRB1*1501 haplotype [7]. Other immune-related genetic susceptibility factors for MS include the genes for IL-2 and IL-7RA [8], and regions of the genome that include the genes for CD58, STAT3, TNFR1 and LTK [9].

Environmental susceptibility factors include low vitamin D levels [10], geographical distance from the equator [11], smoking [12], infection with Epstein-Barr virus [13,14] and development of mononucleosis in adolescence [15]. Although it has not been identified as a risk factor, dysregulation of microbiota of patients with MS was recognized [16-18]. MS was first thought to be caused by an infectious agent; however, no infectious agents have been consistently and reliably identified. It is widely accepted that MS is an autoimmune disease. The ways by which autoimmunity is initiated in the CNS are still debated, but theories of how autoimmune responses are induced include molecular mimicry, bystander activation [19] and epitope spreading [20,21].

Future 8 Medicine 


\section{Acute inflammation \& repair of the CNS during RRMS}

Although the cause of MS remains unclear, studies from the clinic and from preclinical models have given insights into the mechanisms at play once the disease is initiated. During acute-phase MS there is cooperation between innate and adaptive immune responses, but lesions and damage are primarily driven by adaptive immune responses.

$\mathrm{T}$ cells are the primary drivers of disease in MS. Evidence for this includes the presence of $\mathrm{T}$ cells in lesions of patients with MS and detection of autoreactive T cells in blood and cerebrospinal fluid (CSF) of patients with MS [22-24]. In addition, autoreactive $T$ cells are able to induce disease in murine model of MS, experimental autoimmune encephalomyelitis (EAE) [25,26]. T helper cells (Th cells) play a prominent role in the pathogenesis of MS and EAE. The pathogenic effector function of Th cells is the recognition of autoantigen and secretion of pro-inflammatory cytokines, including IL-17 and IFN- $\gamma[26,27]$. $\mathrm{CD} 8^{+} \mathrm{T}$ cells are present in the brains of patients with MS [28] and play a pathogenic role in some models of EAE [29]. Although T cells promote pathogenesis, regulatory $\mathrm{T}$ cells play protective roles in MS: for example, Tr1 cells that secrete IL-10, Foxp3+ Tregs that secrete TGF- $\beta$ or act via direct cell contact [30,31], and regulatory $\mathrm{CD}^{+} \mathrm{T}$ cells [32].

B cells also play an important role in MS. Oligoclonal bands were documented in the CSF of patients with MS [33]. Immunoglobulin deposits can be found in areas of demyelination [34], and brain samples from patients with relapsing MS displayed perivascular cuffing consisting of plasma cells within plaques [35]. Further dissection of pathogenic mechanisms of B cells from pre-clinical models implicate B cells as pathogenic via autoantibody-induced demyelination [36-39], autoantigen presentation [40,41] and antibody-dependent activation of complement [42-44]. B cells can also secrete proinflammatory cytokines [45-47] and play a role in the establishment of tertiary lymphoid organs (TLOs) $[46,48]$. However, B cells can also provide protective functions. For example, antibodies can promote remyelination [49,50], and B cell subsets can secrete anti-inflammatory IL-10, TGF- $\beta$ and IL-35 [51].

It remains unclear what causes relapses, but systemic infection [52] and parturition [53] increase risk of relapse. Remission is associated with immune regulatory functions and repair of the CNS. For example, it is known that regulatory T cells, such as Tr1 and Foxp3+ Tregs, and CD56-bright NK cells downregulate inflammation during EAE [54]. Additionally, remyelination plays an important role in recovery [55,56]. The clearance of myelin debris by microglia is also critical for remyelination and preventing progression of disease [57-59]. Importantly, promotion of the health of neurons is central to the prevention of progression [60].

\section{Progression of MS \& the role of metabolism}

A persistent, low level of inflammation is present in the CNS of many patients with SPMS [61]. Lesions contain cells such as activated glia including astrocytes and microglia, some apoptotic oligodendrocytes (OLs) and demyelinated and transected axons [61-64]. Aside from the potential role of B cells within TLOs, evidence for a contribution of adaptive immunity to progressive disease remains minimal in patients with SPMS [65]. Demyelination and axonal injury are currently considered the primary drivers of progression [61]. In particular, progression of symptoms correlates significantly with axonal injury [66,67], and axon loss determines permanent neurological disability in mouse models of MS [60]. Neuronal injury is promoted by the lack of metabolic and homeostatic support from glia. The support provided by glia includes supply of metabolic intermediates such as lactate, contributions to ion homeostasis and increased redox capacity. Evidence suggests that lack of metabolic and homeostatic support of neurons by glia is essential to the progression of MS. We will provide a review of healthy neuronal metabolism and homeostatic mechanisms and then elucidate evidence of metabolic dysregulation of neurons and glia in MS and progression of MS, summarized in Figure 1.

\section{Healthy brain metabolism \\ Neuronal/axonal metabolism}

In healthy individuals, neurons require large amounts of adenosine triphosphate (ATP) to power ion transporters used to maintain membrane potential and mitochondrial health, and prevent cell death [68]. Neurons are also sensitive to oxidation, and tight regulation of oxidative stress is imperative for neuronal health [69,70]. To support their ATP needs while minimizing oxidative stress, neurons use oxidative metabolism with lactate as a substrate [7174], utilizing lactate over glucose [75,76]. The use of lactate over glucose allows for the production of nicotinamide adenine dinucleotide phosphate (NADPH) by the pentose phosphate pathways which provides a substrate for glutathione (GSH) reductase to reduce oxidized glutathione [77]; GSH being one of the primary antioxidative molecules in the brain [78]. Lactate metabolism allows more glucose to be shuttled into the pentose phosphate pathway while sustaining ATP production. Neurons can take up glucose with GLUT3 [79]; however, they have a 


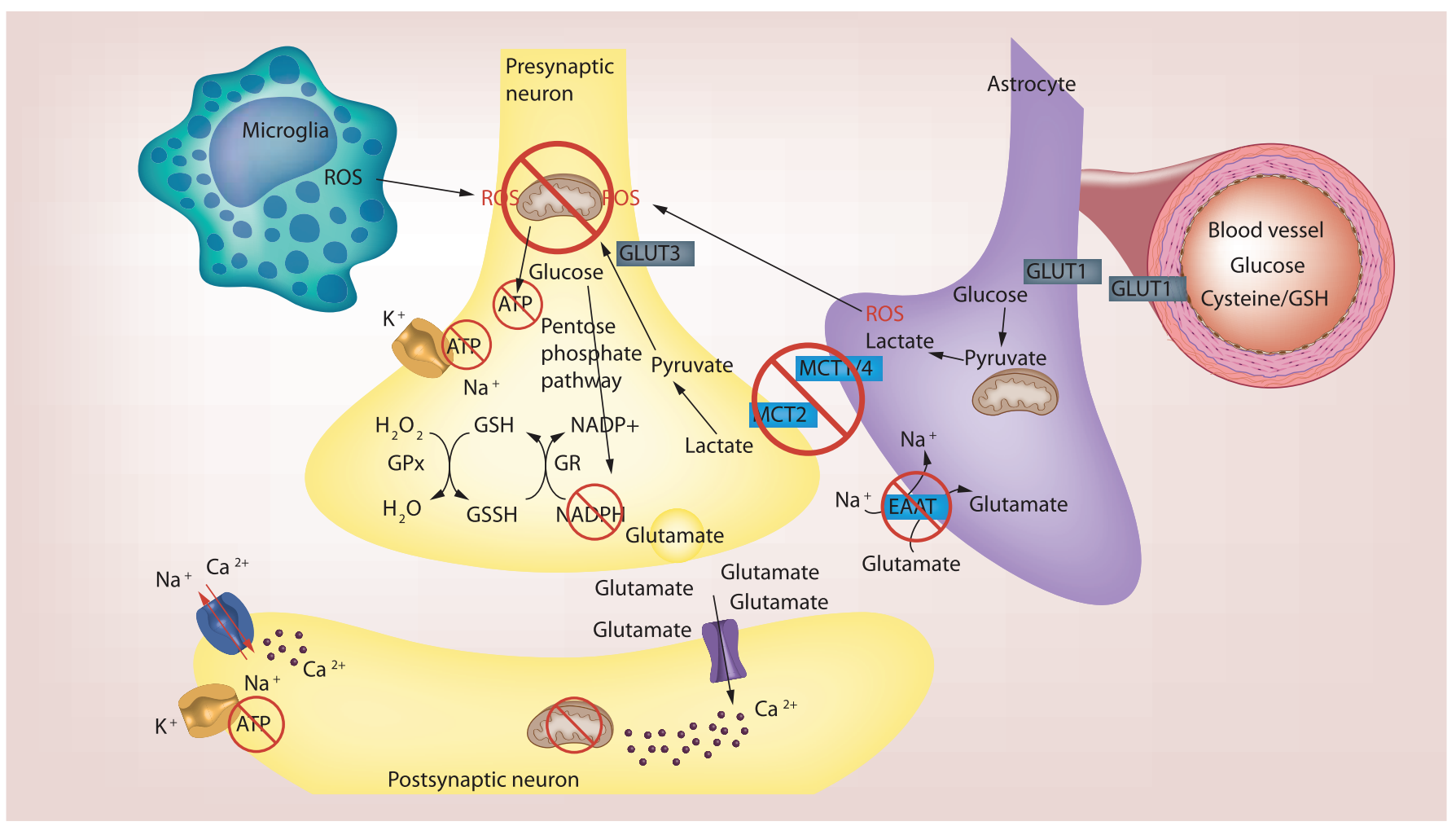

Figure 1. Proposed model of pathogenic dysregulation in metabolic coupling of neurons and glia during multiple sclerosis.

Microglia and astrocytes secrete reactive oxygen species and reactive nitrogen species that damage components of the electron transport chain leading to decreased ATP production in neurons. Decreased lactate transporters on neurons lead to decreased lactate delivery, which results in less ATP production and redox capacity via decrease in glucose utilized in the pentose phosphate pathway and NADPH production. This leads to decreased glutathione recycling, and less neutralization of reactive oxygen species. Decreased glutamate uptake leads to calcium influx and mitochondrial damage. Decreased availability of ATP to power sodium/potassium pumps results in increased intracellular sodium leading to reverse functioning of sodium/calcium exchangers and increased intracellular calcium leading to further damage to mitochondria.

Reproduced with graphics purchased from Modfolio (2018).

slow rate of glycolysis due to low levels of PFK1 [77]. In this way, glucose is shuttled to the pentose phosphate pathway instead of glycolysis to produce NADPH instead of NADH, while lactate can be used to maintain pyruvate and ATP levels [77]. The importance of this mechanism was demonstrated when activation of glycolysis in neurons lead to neuronal death by oxidative stress [77], and inhibition of GSH synthesis lead to mitochondrial damage [80].

Adding to this, ion homeostasis is important for ATP production by maintaining mitochondrial health. In particular, increased intracellular calcium can lead to the opening of the mitochondrial permeability transition pore which leads to depolarization of the mitochondria, decreased ATP production and release of reactive oxygen species (ROS) and reactive nitrogen species (RNS) [81]. Thus, neurons require high levels of ATP, but in order to produce high levels of ATP, they must also maintain antioxidative potential and ion balance during most metabolic processes.

Neurons depend heavily upon glia to meet the ATP requirements both directly by providing metabolic intermediates such as lactate and indirectly by preventing mitochondrial damage. This coupling of neuronal and glia metabolism, originally defined as the coupling of synaptic activity and glucose utilization, is known as metabolic coupling. The first evidence of metabolic coupling came from work by Magistretti et al. and was further characterized later [82-84].

\section{Astrocytes metabolically support neurons}

Astrocytes are important for metabolic coupling and homeostatic support of neurons. Astrocytes produce GSH that protects against oxidative stress and damage to neuronal mitochondria [69]. Astrocytes produce and trans- 
port metabolic intermediates including lactate [85-87], prevent glutamate excitotoxicity which protects neuronal mitochondria [82], and aid in the regulation of ionic balance which also protects neuronal mitochondria [88].

As mentioned previously, NADPH and GSH are important for preventing oxidative stress-induced death of neurons [77]. Neurons rely on astrocytes to help with GSH recycling and production in order to protect against oxidative stress. GSH reduces peroxides in combination with the enzyme GPx [89]. After this reaction, oxidized GSH is recycled back to the reduced form by NADPH and GR [90]. Utilization of the pentose phosphate pathway allows for NADPH production [77]. Astrocytes provide the opportunity for neurons to utilize metabolic pathways that promote NADPH production by providing lactate for ATP formation (discussed in the following section) to free glucose for use in the pentose phosphate pathway [77,91]. In this way, astrocytes are important for recycling of GSH in neurons.

Neurons also rely on astrocytes for the precursors for GSH synthesis. GSH is produced in two steps by GCS and GS utilizing glutamate, glycine and cysteine [92]. In the first, rate-limiting step, glutamate and cysteine are ligated by GCS [92]. GS then converts the dipeptide into GSH [92]. The first step of GSH synthesis occurs in both astrocytes and neurons [93]. However, neurons have a low availability of the rate-limiting substrate, cystine [93]. Astrocytes secrete GSH into the extracellular space via multidrug resistance proteins [94] where it is cleaved by GGT and can be quickly taken up by neurons in the form of CysGly or cystine [95,96]. The importance of this system was demonstrated by treatment of mice with inhibitors of GCS synthesis, which lead to damage of mitochondria [80].

Astrocytes are also important for uptake of glucose and supplying neurons with lactate. Astrocyte vascular processes encase intracerebral blood vessels and take up glucose via GLUT1 on their cell surface [97]. Astrocytes utilize aerobic glycolysis to degrade glucose and produce lactate even in the presence of oxygen in a process known as the Warburg effect $[75,98]$. Much of the lactate formed is released into the extracellular space via MCT1, MCT2, high-capacity cation channel and pannexins $[75,76,82,99-102]$. Lactate is then taken up by neurons via MCT2 where it is broken down and used to generate ATP [71-73,75,76]. As discussed earlier, use of lactate reduces the need for glycolysis that promotes cell death by oxidative stress due to decreased formation of NADPH to recycle oxidized GSH and decrease oxidative stress [77]. This transport system, coupled with glutamate uptake stimulating glucose utilization by astrocytes (discussed next), is also known as the neuron-astrocyte lactate shuttle [82].

Astrocytes aid in preventing glutamate excitotoxicity of neurons. Glutamate excitotoxicity is a process by which the excitatory neurotransmitter, glutamate, remains in the synapse. This leads to prolonged opening of an ionotropic receptor, NMDA receptor, allowing excess influx of calcium resulting in mitochondrial damage and cell death over time known as excitotoxicity [103]. Astrocytes prevent excitotoxicity by clearing glutamate via excitatory amino acid transporters (EAATs) [104-106]. EAAT-3 knock-out mice exhibit increased neurodegeneration and reduced GSH levels [96]. Uptake of glutamate by astrocytes also stimulated glucose metabolism by astrocytes and increased production of lactate that was then shuttled back to neurons [82]. Additionally, glutamate can be converted to glutamine in astrocytes and released. The glutamine that is released can then be taken up by neurons where it is converted to GSH [107]. In these ways, astrocytes are critical to the health of neurons by providing metabolic intermediates, increasing antioxidant capacity, promoting ion homeostasis and mitochondrial health.

\section{OLs metabolically support neurons}

OLs are also important for the support of neuronal metabolism [108-110]. OLs do not play as big of a role in redox regulation of neurons as astrocytes do. OLs are highly susceptible to oxidative stress themselves (in part because of a high iron content) [111], and depleting GSH is particularly damaging to pre-OLs [112]. Despite their low redox capacity, OLs, like astrocytes, produce lactate and shuttle lactate via MCT1 to neurons through MCT2 for ATP production $[108,113]$. In fact, preventing lactate transfer from OLs to neurons by deleting lactate exporters from OLs results in formation of axonal spheroids and degeneration [110]. While OLs express glutamate uptake receptors, EAAT-1 and EAAT-2 [114], they are susceptible to excitotoxicity [115].

Another critical role of OLs is to provide metabolic support for neurons by decreasing metabolic load. OLs are important in aiding conduction of impulses along the axon in a process known as saltatory conduction [116]. In support of this, shiverer mice, which lack myelin basic protein, a major component of CNS myelin, exhibit neurodegeneration and axonal swelling over time [117], and in other animal models, deletion of OLs leads to degeneration due to disruptions in the paranodes and nodes of Ranvier that are important for saltatory conduction $[118,119]$. In decreasing the need for ATP, OLs also maintain ion homeostasis. For example, if the ATP-driven sodium pump is not operational, then sodium accumulates inside of the cell. The sodium is then replaced by calcium through a 
gradient-dependent sodium/calcium pump. The increase in intracellular calcium then can lead to mitochondrial dysfunction and cell death.

In summary, OLs are particularly important for shuttling lactate to neurons, decreasing metabolic load and regulation of glutamate uptake and ion balance; however, OLs are highly susceptible to oxidative stress themselves.

\section{Microglia can metabolically support neurons}

Microglia are yolk sack-derived resident immune cells of the CNS with transcriptional similarity to monocytes and macrophages. Microglia can also metabolically support neurons under healthy conditions, but can become reactive and detrimental in diseased states. Microglia can produce GSH, clear myelin debris and ROS/RNS, secrete lactate and can clear glutamate, all of which can promote neuronal mitochondrial health. Microglia are important for aiding in decreasing oxidative stress of neurons through production of GSH [120,121], and clearance of myelin debris and oxidized lipids [57,59]; however, these are typically only found in diseased states.

Microglia can also deliver lactate to neurons, particularly MCT1 and MCT2 are upregulated when macrophages are activated during ischemia [122]. However, microglia are not known as a primary source of lactate. In contrast, an astrocyte-microglia shuttle has been proposed [123].

Microglia are not known to express EAATs in healthy individuals, suggesting they may not play a large role in preventing glutamate excitotoxicity in healthy conditions; however, EAATs are induced in microglia under pathological conditions and it has been suggested that this is a compensatory mechanism to aid neuron metabolism and/or to aid in their own production of GSH [124,125]. In fact, it was shown that microglia aid in preventing excitotoxicity [126]. Microglia migrate to damaged neurons by sensing ATP release and wrap around neurons to induce neuronal repolarization; however, the mechanism by which they induce repolarization was not determined [126].

In summary, microglia have the capacity to produce and secrete GSH, secrete lactate and play an important role in the clearance of ROS/RNS, and aid in preventing glutamate excitotoxicity. Microglia are highly dynamic and the role of these cells in the metabolic support and metabolic inhibition of neurons is primarily observed in diseased states.

\section{Metabolic dysregulation during progression of MS}

Virtual hypoxia, an increase in energy demand coupled with a decrease in the ability to supply it, has been suggested to be a driver of neuronal death in MS [55]. Virtual hypoxia is primarily thought to be caused by increased demand for ATP to drive sodium/potassium pumps to propagate action potentials after the myelin sheath has been damaged [55]. Virtual hypoxia leads to mitochondrial injury, glutamate excitotoxicity and defects in mitochondrial transport [55,127]. Neuronal death and progression of MS is associated with oxidative stress [128], impairment of remyelination, and accumulation of debris [57-59], all of which can lead to an increase metabolic demand on neurons by damaging mitochondria. Dysregulation in metabolic support of neurons by glia can contribute to virtual hypoxia during SPMS.

\section{Neuronal metabolic dysregulation during progression of MS}

There is evidence of metabolic dysregulation of neurons of patients with SPMS, and of mitochondria in particular. A decrease in complex IV activity of neuronal mitochondria was documented from brains of individuals with SPMS, and inhibition of mitochondrial respiratory-chain complex IV augmented glutamate-mediated axonal injury in vitro [129]. Decreased mRNA levels of mitochondrial genes and activity of mitochondrial complex I and III were identified in brains of individuals with SPMS [130]. Ion homeostasis and ROS/RNS can also affect mitochondrial function. Increased intracellular sodium levels lead to the sodium/calcium exchanger to operate in reverse which causes calcium influx and mitochondrial damage [131]. An increase in ROS and an ion imbalance are present in neurons of individuals with MS. There is an increase in intracellular sodium and increased sodium levels within lesions [132,133]. Additionally, highest sodium concentration as measured by sodium magnetic resonance imaging (MRI) was observed in patients with SPMS and patients with greater disability [134]. Additionally, RNS, such as peroxynitrate, damage complexes I and IV [135-137]. Reports of positive staining of peroxynitrate, nitrotyrosine and other markers for oxidative stress in brains from individuals with SPMS indicate that there are both ROS and RNS formed during this phase of disease and may contribute to neuronal damage [128,138]. As mentioned before, there is a notable decrease in complex IV activity in brains of individuals with SPMS, indicating a potential role for RNS [129]; however, whether or not the mitochondrial complexes show evidence of damage from ROS and RNS, such as nitrosylation has not been reported in patients with SPMS. 


\section{Astrocyte contributions to metabolic dysregulation of neurons during progression of MS}

Astrocytes contribute to progression of MS through the inhibition of remyelination by formation of a glial scar that prevents differentiation of OL precursor cells [139-142]. Astrocytes impair neuronal metabolism by releasing cytotoxic factors, including ROS and RNS, which interfere with neuronal mitochondrial function [138,141]. There is also evidence of dysregulation of lactate shuttling and glutamate uptake during SPMS.

Astrocytes have the capacity to express both pro- and anti-oxidant molecules. Accordingly, there is evidence of expression of pro-oxidant molecules in SPMS. Activated astrocytes in patients with SPMS express mRNA and stain positive for inducible nitric oxide synthase, nitrotyrosine and superoxide forming enzyme, NOX [138,143].

While not shown specifically in astrocytes, there is a dysregulation in components important for GSH production and transport to neurons during MS. In fact, polymorphisms in genes for GSH S-transferases are associated with severe disability in patients with disease duration greater than 10 years [144]. Additionally, GSH was decreased in the CSF of patients with MS [145] and there was decreased GPx activity and increased GR activity in the CSF of patients with MS [146]. Interestingly, the decrease in GSH biosynthesis is associated with a dysregulation of the upstream transcription factor, Nrf2 [147,148]. In patients with MS, however, Nrf2 is upregulated in astrocytes and OLs in acute and chronic lesions [149].

The neuron-astrocyte lactate shuttle is also dysregulated in lesions of patients with SPMS. In non-neurological disease control patients, glucose transporters and MCT were expressed in many cells, and particularly in microglia and endothelial cells. In contrast, in patients with MS, glucose transporters and MCTs were highly expressed by infiltrating macrophages and reactive astrocytes in active lesions. In inactive lesions, astrocytes showed increased MCT1 staining; however, demyelinated axons showed reduced GLUT3 and MCT2 immunoreactivity [150]. Patients with MS exhibit reduced expression of genes involved in the astrocyte-neuron lactate shuttle, and the glutamateglutamine cycle in whole tissue normal appearing grey matter, including genes for MCT1, MCT4, GLUT1, among others [151]. Moreover, a Toll-like/IL-1 $\beta$ signaling expression signature occurred in tandem with the reduced expression of genes associated with astrocyte-neuron lactate shuttle and the glutamate-glutamine cycle prompting the hypothesis that IL-1 $\beta$ signaling to astrocytes could lead to the downregulation of those genes. Indeed, IL-1 $\beta$ and LPS treatment of astrocytes downregulated the lactate shuttle and glutamate-glutamine cycle in vivo, and immune activation with CFA and pertussis toxin lead to downregulation of MCT1 in the spinal cord of C57BL/6 mice [151]. The downstream pathways connecting TLR/IL-1 $\beta$ signaling and downregulation of these genes have yet to be elucidated. Interestingly, increased lactate in CSF was associated with progression of MS [152]. However, lactate levels in MS patient CSF have been reported as increased, unchanged or even decreased, and therefore more investigation is needed before coming to final conclusions [152,153]. Taken together, current evidence suggests that while astrocytes can secrete lactate during MS/EAE, it is not efficiently taken up by neurons.

Finally, there are indications of dysregulation in glutamate recycling, although this has not been explicitly linked to astrocytes. Levels of glutamate are increased in blood, CSF and CNS of patients with MS [154]. Patients with MS have reduced expression of genes involved in the glutamate-glutamine cycle in normal appearing grey matter, including genes for EAAT-1, EAAT-2, GS, GLUT1, among others [151].

In summary, astrocytes release ROS that damage neuronal mitochondrial function and there is dysregulation of lactate shuttling, GSH production and recycling, and glutamate uptake during SPMS.

\section{$O L$ contribution to metabolic dysregulation of neurons during progression of $M S$}

Unsurprisingly, OL dysregulation is notable in MS as myelin antigens are primary targets of the autoimmune attack [155-157]. Much of the current research efforts are centered on OLs themselves and less on their contribution to neuronal metabolism. Here, we focus primarily on alterations of OL support of neurons in MS and EAE.

Axonal mitochondrial swelling has been observed in both myelinated axons and demyelinated axons during EAE $[119,158]$, demonstrating that demyelination alone is not a requisite for neuronal death. The myelin sheath plays a role in survival of neurons as discussed earlier. MCT channels that shuttle lactate and other metabolic intermediates between OLs and neurons are dysregulated during SPMS, although the MCT expression is not OLs specific [150]. There was decreased expression of glutamate uptake receptors, EAAT-1 and -2, in the OLs around lesions, and TNF- $\alpha$, a proinflammatory cytokine secreted in lesions, decreases EAAT-1 expression and inhibits glutamate uptake by greater than $75 \%$ in cultures of OLs [114]. Conceivably, this could contribute to glutamate excitotoxicity of both neurons and OLs. 
OLs are important for saltatory conduction. As mentioned previously, there is an increase in intracellular sodium and increased sodium levels within lesions [132,133], and, as mentioned previously, the highest sodium concentration on sodium MRI was present in patients with SPMS and greater disability [134]. After demyelination there are notable changes observed in sodium channel distribution along axons [159], indicating that saltatory conduction aids in maintaining proper ion homeostasis.

Deficiencies in MCT channels, EAAT-1 and -2 in OLs, and ion imbalance indicate that OL damage can lead to the death of neurons as well; however, more research is needed to directly assess metabolic contribution between neurons and OLs during and leading up to SPMS.

\section{Microglial contribution to metabolic dysregulation of neurons during progression of MS}

Microglia contribute to MS progression primarily through release of ROS that can lead to mitochondrial damage $[143,160,161]$. There are microglia-associated changes in metabolic intermediates and glutamate transporters [162]; however, microglia also have self-regulatory mechanisms $[163,164]$, and are also crucial to the remyelinating process through clearance of myelin debris [57-59]. Microglia have been associated with both reparative processes as well as damaging processes in SPMS [61].

Microglia express enzymes important for creating ROS in patients with SPMS, including NOX and MPO [143,160,161].

Although increased GSH levels have been identified from microglia in culture and in other disease systems [120,121], less is known about microglial GSH systems in SPMS. Similarly, while an increase in MCT1 and MCT2 expression was documented in ischemia, it has not been shown in SPMS [122].

Activated microglia are implicated in the downregulation of EAAT-1 and -2 that could lead to excitotoxicity during SPMS [162], and activation of microglia leads to the increase in cystine/glutamate exchanger in both cultured microglia, peripheral blood and postmortem optic nerve samples of MS patients, and in spinal cords of mice with EAE [165]. The levels of glutamate, or if it caused excitotoxicity, was not investigated.

Microglia have self-regulatory mechanisms. For example, CX3CL1 upregulates Nrf2 [163], and TNF- $\alpha$ treatment of microglia cells lead to an increase in GSH levels that reduced ROS mediated cell death [164]. However, not much is known about dysregulation these pathways during SPMS. Similarly, while microglia are crucial to the remyelinating process through clearance of myelin debris [57-59], this was not demonstrated in the context of SPMS. Moreover, microglia possess the capability to suppress ROS and RNS, provide metabolic intermediates, repolarize cells, clear debris and promote remyelination. However, in SPMS they also produce ROS, and have a reduced capacity to take up glutamate. More research is needed to directly assess protective roles of microglia in SPMS.

To summarize, neurodegeneration plays a central role in progression of MS. Astrocytes, OLs and microglia play important support roles for neurons by the preventing the accumulation of ROS-mediated mitochondrial damage, aiding in ion homeostasis, preventing neurotransmitter imbalance and virtual hypoxia. During MS these functions are dysregulated leading to axonal and neuronal death and progression of symptoms.

\section{Pain in MS \& the role of metabolism}

One particularly troublesome aspect of progression of MS is chronic neuropathic pain experienced by over half of patients during the course of their disease $[166,167]$. Chronic neuropathic pain is more often associated with progressive forms of the disease [168]. This leads to the question of what causes this pain, how pain is associated with mechanisms of progression, and whether pain and progression can be treated together by targeting common disease mechanisms.

\section{Nociceptive pain processing}

Typically, nociceptive pain is processed through activation of nociceptors that synapse in the dorsal horn of the spinal cord. The depolarization of the nociceptors leads to the release of excitatory neurotransmitters, glutamate and substance $P$ in the dorsal horn of the spinal cord. The release of neurotransmitters signals second-order neurons in the spinothalamic tract to depolarize and transduce the signal to the thalamus where they synapse with the third-order neurons that continue into the somatosensory cortex. Pain can be modulated throughout this pathway and is often modulated by synaptic processing in the dorsal horn of the spinal cord. In this process, inhibitory interneurons in the spinal cord release GABA that inhibits depolarization by binding the ligand-gated ionotropic $\mathrm{GABA}_{\mathrm{A}}$ receptors on the second-order neurons and increasing intercellular chloride ions. 


\section{Chronic neuropathic pain in SPMS}

Chronic neuropathic pain during MS is caused by demyelination, neuroinflammation and axonal damage [169] and as an indirect consequence of active demyelinating lesion in areas such as the dorsal horn of the spinal cord or the thalamus [170]. One mechanism of chronic neuropathic pain is central sensitization at the synapse in the dorsal horn of the spinal cord. Central sensitization is an increase in the synaptic transmission of pain signals. This increase in transmission is produced in a number of ways, including activity-dependent phosphorylation and trafficking of receptors or ion channels, transcriptional changes, structural alterations of synaptic contacts and reduction of inhibitory mechanisms by loss of interneurons [171]. Loss of inhibitory interneurons is of particular interest for chronic neuropathic pain in progression of MS, and lesions are evident along the pain processing pathway of patients with MS. Along these lines, analysis of the association of chronic neuropathic pain and lesion location showed that $33 \%$ of the patients with chronic pain showed hyperintensities on MRI in the lateral and medial thalamic regions; however, the authors also implicated chronic neuropathic pain as a result of spinal cord lesions due to the bilateral nature of the pain [172].

\section{Pain during EAE}

Neuropathic pain has been characterized in EAE; however, there are few studies investigating the mechanisms underlying pain in these models [173-175]. One study of interest observed pain associated with reactive gliosis in the dorsal horn of the spinal cord during EAE [174]. Later work attributed increased responsiveness to pain after subcutaneous formalin injection to decreased glutamate transporter expression [176]. Nevertheless, more studies are needed to access mechanisms of chronic neuropathic pain in preclinical models of MS.

\section{Inhibitory interneuron dysregulation}

A decrease in the inhibitory neurotransmitter GABA in the spinal cord during EAE has been reported [177-180], as well as in the CSF of patients with MS [181-183]. However, conflicting results have also been reported [184]. Further in support of the notion that inhibitory interneurons are dysregulated in MS, selective loss of parvalbumin-positive interneurons was shown in the primary motor cortex of mice with EAE and patients with MS [185]. This study did not address parvalbumin-positive interneurons in the dorsal horn of the spinal cord; however, ablation of parvalbumin-positive neurons in the dorsal horn produces neuropathic pain-like mechanical allodynia in mice [186]. These studies were corroborated by work that found reduced components of GABAergic neurotransmission and reduced density of inhibitory interneuron processes in the cortex of patients with SPMS [130]. Furthermore, there is also evidence of selective NMDA receptor-mediated neuronal death by secretion of nitric oxide by astrocytes [187].

\section{Pain \& dysregulation of metabolic support}

Although not yet demonstrated in experimental models of MS, induction of chronic neuropathic pain by ligation of L5 and L6 spinal nerves revealed dysregulation of a large number of genes associated with metabolism and neurodegeneration. These genes included downregulation in sodium/potassium and sodium/calcium exchange channels, glutamate receptor and mitochondrial creatinine kinase [188] indicating that these metabolic support factors can play a critical role in chronic neuropathic pain. Astrocyte glutamate/glutamine shuttling also plays an important role in central sensitization in the dorsal horn [189]. As mentioned previously, the altered pain sensitivity in mice with EAE was linked to a decrease in glutamate transporter expression [176].

In summary, dysregulation of excitatory neurotransmitter uptake, and death of inhibitory interneurons in the dorsal horn of the spinal cord can lead to pain in MS, and dysregulation of excitatory neurotransmitter uptake and death of neurons contribute to progression of MS. Additional mechanisms are likely to play a role and need to be elucidated.

\section{Treatments to promote neuronal survival via metabolic support to prevent progression \& chronic neuropathic pain in MS}

Various metabolic complications contribute to pain and progression of MS, including mitochondrial injury [127], oxidative stress [128], ion imbalance and virtual hypoxia [55]. To suppress progression and pain in MS, protection of neuronal metabolic, antioxidative and ion homeostasis is paramount. Current treatments are particularly adept in addressing inflammation; however, few show benefits for progressive forms of MS and complications associated with progression such as chronic neuropathic pain [4]. In order to treat progression and pain, the addition of treatments that support metabolic coupling between neurons and glia may be of benefit. Here we highlight some studies that 
Table 1. Potential treatment avenues to address metabolic dysregulation leading to secondary progressive multiple sclerosis and chronic neuropathic pain during multiple sclerosis.

\begin{tabular}{|c|c|c|c|}
\hline Treatment & Mechanism & Effect on pain & Effect on progression \\
\hline \multicolumn{4}{|l|}{ Transfer of lactate } \\
\hline IGF-1 & Lactate transfer by upregulating $\mathrm{MCT} 2$ & Not assessed & No effect [219] \\
\hline \multicolumn{4}{|c|}{ Decrease ROS and RNS } \\
\hline Dimethyl fumarate & Activates Nrf2 & $\begin{array}{l}\text { Reduced pain behaviors in murine } \\
\text { model of arthritis [197] }\end{array}$ & No indication of progression [195] \\
\hline $\mathrm{N}$-acetyl cysteine & Glutathione synthesis & $\begin{array}{l}\text { Marginal improvement from baseline in } \\
\text { clinical trials }\end{array}$ & Clinical trial in progress \\
\hline MitoQ & Mitochondria-targeted ROS scavenger & Not reported & $\begin{array}{l}\text { Attenuated disease severity and neuronal } \\
\text { loss during EAE }[198,199]\end{array}$ \\
\hline \multicolumn{4}{|c|}{ Decrease calcium influx } \\
\hline MS153 & $\begin{array}{l}\text { Increase activity of glutamate } \\
\text { transporter }\end{array}$ & $\begin{array}{l}\text { Normalizes pain responses in mice with } \\
\text { EAE [176] }\end{array}$ & Not reported \\
\hline Ceftriaxone & $\begin{array}{l}\text { Increased expression of glutamate } \\
\text { transporters }\end{array}$ & $\begin{array}{l}\text { Decreased tactile hypersensitivities in } \\
\text { mice with EAE }[201,202]\end{array}$ & Not reported \\
\hline Memantine & Block NMDA receptors & Not reported & $\begin{array}{l}\text { Worsening of neurological symptoms in } \\
\text { MS [206] }\end{array}$ \\
\hline Amantadine & Block NMDA receptors & $\begin{array}{l}\text { Decreases fatigue in patients with } \\
\text { MS [207] }\end{array}$ & Lessens neuropathy in EAE [205] \\
\hline MK-801 & Block NMDA receptors & Not assessed & Lessens neuropathy in EAE [204] \\
\hline \multicolumn{4}{|l|}{ Ion homeostasis } \\
\hline Phenytoin & Na channel blocker & Prevents pain in MS patients [216] & Not assessed \\
\hline Flecainide & Na channel blocker & Not assessed & Not assessed \\
\hline Lamotrigine & Na channel blocker & Not assessed & Early cerebral volume loss in patients [217] \\
\hline Gabapentin & Gaba analogue & Decreased pain and spasticity [218] & Not assessed \\
\hline \multicolumn{4}{|l|}{ Other } \\
\hline Fingolimod & $\begin{array}{l}\text { Decreases central sensitization, S1P } \\
\text { modulation, astrocyte suppression }\end{array}$ & Decreased pain responses in $\mathrm{EAE}$ & $\begin{array}{l}\text { Lower disease severity compared with } \\
\text { control in progressive EAE model. } \\
\text { Did not slow primary progressive MS. } \\
\text { Improved the risk of progression of } \\
\text { disability in RRMS [208-211] }\end{array}$ \\
\hline
\end{tabular}

EAE: Experimental autoimmune encephalomyelitis; NMDA: N-methyl-d-aspartate; RNS: Reactive nitrogen species; ROS: Reactive oxygen species; RRMS: Relapsing-remitting multiple sclerosis.

investigated benefits for treatment of progression and/or pain by promoting metabolic support of neurons and decreasing metabolic load on neurons (summarized in Table 1).

\section{Treatments promoting metabolic support of neurons}

Conceivably, an increase in the delivery of metabolic intermediates such as lactate and promotion of mitochondrial health through redox and ion homeostasis may help survival of neurons and prevent progression and neuropathic pain in MS. While lactate can promote proinflammatory phenotypes in immune cells [190], increase in the uptake of lactate by neurons can be promoted specifically by an increase in MCT2 expression [71]. MCT2 expression is promoted by IGF-1 and insulin [191]. IGF-1 treatment reduces disease severity in EAE and decreases demyelination [192]. However, while well tolerated in a small study $(n=7)$ over 24-weeks, there was no significant difference in MRI or clinical measures between baseline and IGF-1 treatment of patients with MS. Chronic neuropathic pain was not assessed in this study; however, it was reported that IGF-1 can increase peripheral pain by stimulation of calcium channels [193]. This demonstrates the necessity of identifying more specific targets that can drive MCT2 expression.

Promoting mitochondrial health by decreasing oxidative stress and restoring ion homeostasis could also help restraining chronic neuropathic pain and progression of MS. Nrf2 activation in glia protects neurons from oxidative stress [147] and increases the expression of the shuttle for GSH, MRP1 [194]. The Nrf2 activator, dimethyl fumarate (DMF), is an approved disease modifying therapy for patients with MS. In a pilot study of DMF treatment of patients with progressive forms of MS over $75 \%$ of the patients showed no indications of progression [195]. The INSPIRE clinical trial (NCT02430532) for patients with SPMS was terminated by the sponsor for business 
reasons. Nevertheless, DMF increased GSH production by OLs [196] and inhibited pain behaviors in a model of arthritis [197]. Although mitochondrially targeted ROS scavengers have not yet been extensively investigated in MS or EAE, MitoQ, a derivative of Co-enzyme Q10, attenuated disease severity as well as neuronal loss in the spinal cord during EAE [198,199].

Increase in GSH intermediates, such as cysteine in the form of oxidant scavenger n-acetyl cysteine (NAC), is beneficial in acute EAE [200]. A clinical trial assessing NAC in MS started in 2017 (NCT03032601) and results are not yet available. In another clinical trial assessing NAC to supplement morphine for chronic neuropathic pain (NCT01840345), patients marginally improved from baseline; however, average morphine dose increased as well. Thus, the beneficial effects of NAC may have been due, at least in part, to the increase in morphine dose.

Preventing calcium influx and glutamate excitotoxicity can also promote mitochondrial health and, conceivably, slow progression and lessen chronic neuropathic pain. This may be achieved by increasing glutamate uptake and blocking calcium influx through NMDA receptors and sodium/calcium exchangers. The small molecule, (R)-(-)-1-methyl-1-nicotinyl-2-pyrazoline (MS-153) inhibited glutamate release, increased glutamate uptake, and decreased chronic neuropathic pain in EAE [176]. However, no other studies have since been conducted to expand on these results. Similarly, the drug ceftriaxone, also known to increase glutamate transport levels, decreased tactile hypersensitivities in mice with EAE [201,202]. However, this drug is a $\beta$-lactam antibiotic and would be problematic for long-term use in treatment of MS due to complications associated with long-term antibiotic use such as bacterial antibiotic resistance and increased susceptibility to Clostridium diffcile infections.

Blocking signaling of NMDA receptors has shown promise, particularly in rodent models [203]. NMDA receptor antagonists, memantine, amantadine and MK-801 all limit neuropathology in rodent models of MS [204,205]. Memantine is an oral medication used in the treatment of Alzheimer's disease. Unfortunately, a small off-label trial treating patients with MS with memantine was halted when patients reported worsening of neurologic symptoms [206]. Amantadine is often used to prevent fatigue in patients with MS, but pain and progression was so far not assessed [207]. MK-801 treatment has not been tested in patients with MS and neuropathic pain.

Finally, the sphingosine-1 phosphate receptor modulator fingolimod (FTY720), an approved disease modifying therapy for RRMS, decreased chronic neuropathic pain in mice with EAE [208]. Specifically, markers of central sensitization were reduced, including glutamate-evoked calcium signaling of neurons in the dorsal horn of the spinal cord, and it was hypothesized that fingolimod can act by reversing central sensitization. Additionally, fingolimod suppressed astrocyte activation and EAE in the non-obese diabetic, progressive model of the disease [209]. While fingolimod did not slow progression in patients with PPMS [210], it decreased the risk of disability progression in patients with RRMS [211].

\section{Treatments to decrease metabolic load on neurons}

Another approach to increase ATP levels to promote neuronal survival could consist of decreasing the metabolic load on neurons by supporting ion homeostasis and promoting remyelination. There are a number of treatments that have shown promise for promoting remyelination (reviewed in Plemel et al. [212]). In addition, sodium channel blocking agents, including phenytoin [159,213], flecainide [214], lamotrigine [215] aided in preventing neurodegeneration during EAE. Phenytoin prevents pain in patients with MS [216], but progression has not been assessed. As of yet, flecainide has not been tested in patients with MS, and there was early cerebral volume loss in lamotrigine-treated patients when compared with placebo [217]. Finally, the GABA analog, gabapentin, decreases pain and spasticity in patients with MS [218], but studies have not evaluated progression of disease.

\section{Conclusion}

Progression of MS and chronic neuropathic pain remain critical issues in MS despite the advances in current disease modifying therapies that target inflammation. Neurodegeneration plays a central role in progression and pain during MS. Neurodegeneration is promoted by accumulation of ROS, mitochondrial damage, neurotransmitter imbalance, ion imbalance and virtual hypoxia. Glia play a central role in the support of neurons in homeostatic conditions. Moreover, there is evidence of dysregulation in neuron-glia cooperation during SPMS and pain associated with MS. More research is needed to address the specific mechanisms of neuron-glia metabolic cooperation and their dysregulation in MS and how these mechanisms can be targeted to prevent progression and pain in MS patients. 


\section{Future perspective}

In order to prevent progression of MS and to address neurodegenerative and pain aspects of MS pathology, novel treatment paradigms need to be established that move beyond the focus on the acute inflammatory events. This may be achieved by increased focus on cells and specific molecules in the CNS that contribute to metabolic support of neurons. Novel therapeutic approaches to target specific subsets of cells and molecules to promote metabolic support of neurons should be the focus of next-generation drugs.

\section{Executive summary}

- Acute inflammation and adaptive immune responses drive relapsing-remitting multiple sclerosis (MS).

- Neurodegeneration plays a central role in progression of MS.

- Neuron-glia metabolic coupling is important in survival of neurons.

- Neuron-glia metabolic coupling is dysregulated during secondary progressive MS and chronic neuropathic pain.

- More research is needed to determine the mechanisms of neuron-glia metabolic cooperation to prevent pain and progression of MS and develop novel treatments.

Financial \& competing interests disclosure

This work was supported by grants NS42809, NS84201 and G12MD007591 from the National Institutes of Health, and grants RG3701, RG5501 and RG1602 from the National Multiple Sclerosis Society (TG Forsthuber), and The Brown Foundation, Inc (RR Robinson). The authors have no other relevant affiliations or financial involvement with any organization or entity with a financial interest in or financial conflict with the subject matter or materials discussed in the manuscript apart from those disclosed.

No writing assistance was utilized in the production of this manuscript.

\section{References}

Papers of special note have been highlighted as: $\bullet$ of interest; $\bullet \bullet$ of considerable interest

1 Dilokthornsakul P, Valuck RJ, Nair KV, Corboy JR, Allen RR, Campbell JD. Multiple sclerosis prevalence in the United States commercially insured population. Neurology 86(11), 1014-1021 (2016).

2 Tremlett H, Yinshan Z, Devonshire V. Natural history of secondary-progressive multiple sclerosis. Mult. Scler. 14(3), 314-324 (2008).

3 Koch M, Kingwell E, Rieckmann P, Tremlett $\mathrm{H}$. The natural history of primary progressive multiple sclerosis. Neurology 73(23), 1996-2002 (2009).

4 Coret F, Perez-Miralles FC, Gascon F et al. Onset of secondary progressive multiple sclerosis is not influenced by current relapsing multiple sclerosis therapies. Mult. Scler. J. Exp. Transl Clin. 4(2), 2055217318783347 (2018).

5 Kutzelnigg A, Lucchinetti CF, Stadelmann C et al. Cortical demyelination and diffuse white matter injury in multiple sclerosis. Brain 128(Pt 11), 2705-2712 (2005).

6 Lucchinetti CF, Popescu BF, Bunyan RF et al. Inflammatory cortical demyelination in early multiple sclerosis. $N$. Engl. J. Med. 365(23), 2188-2197 (2011).

7 Sawcer S, Ban M, Maranian M et al. A high-density screen for linkage in multiple sclerosis. Am. J. Hum. Genet. 77(3), 454-467 (2005).

8 International Multiple Sclerosis Genetics C, Hafler DA, Compston A et al. Risk alleles for multiple sclerosis identified by a genomewide study. N. Engl. J. Med. 357(9), 851-862 (2007).

9 Sawcer S, Franklin RJ, Ban M. Multiple sclerosis genetics. Lancet Neurol. 13(7), 700-709 (2014).

10 Ascherio A, Munger KL, White R et al. Vitamin D as an early predictor of multiple sclerosis activity and progression. JAMA Neurol. 71(3), 306-314 (2014).

11 Browne P, Chandraratna D, Angood C et al. Atlas of Multiple Sclerosis 2013: agrowing global problem with widespread inequity. Neurology 83(11), 1022-1024 (2014).

12 Ramanujam R, Hedstrom AK, Manouchehrinia A et al. Effect of smoking cessation on multiple sclerosis prognosis. JAMA Neurol. 72(10), 1117-1123 (2015).

13 Plavina T, Subramanyam M, Bloomgren G et al. Anti-JC virus antibody levels in serum or plasma further define risk of natalizumab-associated progressive multifocal leukoencephalopathy. Ann. Neurol. 76(6), 802-812 (2014).

14 Levin LI, Munger KL, O’reilly EJ, Falk KI, Ascherio A. Primary infection with the Epstein-Barr virus and risk of multiple sclerosis. Ann. Neurol. 67(6), 824-830 (2010).

15 Thacker EL, Mirzaei F, Ascherio A. Infectious mononucleosis and risk for multiple sclerosis: a meta-analysis. Ann. Neurol. 59(3), 499-503 (2006). 
16 Chen J, Chia N, Kalari KR et al. Multiple sclerosis patients have a distinct gut microbiota compared to healthy controls. Sci Rep. 6, 28484 (2016).

17 Berer K, Gerdes LA, Cekanaviciute E et al. Gut microbiota from multiple sclerosis patients enables spontaneous autoimmune encephalomyelitis in mice. Proc. Natl Acad. Sci. USA 114(40), 10719-10724 (2017).

18 Rothhammer V, Borucki DM, Tjon EC et al. Microglial control of astrocytes in response to microbial metabolites. Nature 557(7707), 724-728 (2018).

19 Mccoy L, Tsunoda I, Fujinami RS. Multiple sclerosis and virus induced immune responses: autoimmunity can be primed by molecular mimicry and augmented by bystander activation. Autoimmunity 39(1), 9-19 (2006).

20 Lehmann PV, Forsthuber T, Miller A, Sercarz EE. Spreading of T-cell autoimmunity to cryptic determinants of an autoantigen. Nature 358(6382), 155-157 (1992).

21 Lehmann PV, Sercarz EE, Forsthuber T, Dayan CM, Gammon G. Determinant spreading and the dynamics of the autoimmune T-cell repertoire. Immunol. Today 14(5), 203-208 (1993).

22 Babbe H, Roers A, Waisman A et al. Clonal expansions of CD8(+) T cells dominate the T cell infiltrate in active multiple sclerosis lesions as shown by micromanipulation and single cell polymerase chain reaction. J. Exp. Med. 192(3), 393-404 (2000).

23 Hafler DA, Duby AD, Lee SJ, Benjamin D, Seidman JG, Weiner HL. Oligoclonal T lymphocytes in the cerebrospinal fluid of patients with multiple sclerosis. J. Exp. Med. 167(4), 1313-1322 (1988).

24 Lee SJ, Wucherpfennig KW, Brod SA, Benjamin D, Weiner HL, Hafler DA. Common T-cell receptor V beta usage in oligoclonal T lymphocytes derived from cerebrospinal fluid and blood of patients with multiple sclerosis. Ann. Neurol. 29(1), 33-40 (1991).

25 Ortiz-Ortiz L, Weigle WO. Cellular events in the induction of experimental allergic encephalomyelitis in rats. J. Exp. Med. 144(3), 604-616 (1976).

26 Jager A, Dardalhon V, Sobel RA, Bettelli E, Kuchroo VK. Th1, Th17, and Th9 effector cells induce experimental autoimmune encephalomyelitis with different pathological phenotypes. J. Immunol. 183(11), 7169-7177 (2009).

27 Komiyama Y, Nakae S, Matsuki T et al. IL-17 plays an important role in the development of experimental autoimmune encephalomyelitis. J. Immunol. 177(1), 566-573 (2006).

28 Booss J, Esiri MM, Tourtellotte WW, Mason DY. Immunohistological analysis of T lymphocyte subsets in the central nervous system in chronic progressive multiple sclerosis. J. Neurol. Sci. 62(1-3), 219-232 (1983).

29 Huseby ES, Liggitt D, Brabb T, Schnabel B, Ohlen C, Goverman J. A pathogenic role for myelin-specific CD8(+) T cells in a model for multiple sclerosis. J. Exp. Med. 194(5), 669-676 (2001).

30 Astier AL, Meiffren G, Freeman S, Hafler DA. Alterations in CD46-mediated Tr1 regulatory T cells in patients with multiple sclerosis. J. Clin. Invest. 116(12), 3252-3257 (2006).

31 Fletcher JM, Lonergan R, Costelloe L et al. CD39+Foxp3+ regulatory T cells suppress pathogenic Th17 cells and are impaired in multiple sclerosis. J. Immunol. 183(11), 7602-7610 (2009).

32 Sinha S, Boyden AW, Itani FR, Crawford MP, Karandikar NJ. CD8(+) T-cells as immune regulators of multiple sclerosis. Front Immunol. 6, 619 (2015).

33 Kabat EA, Moore DH, Landow H. An electrophoretic study of the protein components in cerebrospinal fluid and their relationship to the serum proteins. J. Clin. Invest. 21(5), 571-577 (1942).

34 Genain CP, Cannella B, Hauser SL, Raine CS. Identification of autoantibodies associated with myelin damage in multiple sclerosis. Nat. Med. 5(2), 170-175 (1999).

35 Tanaka R, Iwasaki Y, Koprowski H. Ultrastructural studies of perivascular cuffing cells in multiple sclerosis brain. Am. J. Pathol. 81(3), 467-478 (1975).

36 Schluesener HJ, Sobel RA, Linington C, Weiner HL. A monoclonal antibody against a myelin oligodendrocyte glycoprotein induces relapses and demyelination in central nervous system autoimmune disease. J. Immunol. 139(12), 4016-4021 (1987).

37 Ponomarenko NA, Durova OM, Vorobiev Ii et al. Catalytic activity of autoantibodies toward myelin basic protein correlates with the scores on the multiple sclerosis expanded disability status scale. Immunol. Lett. 103(1), 45-50 (2006).

38 Marta CB, Oliver AR, Sweet RA, Pfeiffer SE, Ruddle NH. Pathogenic myelin oligodendrocyte glycoprotein antibodies recognize glycosylated epitopes and perturb oligodendrocyte physiology. Proc. Natl Acad. Sci. USA 102(39), 13992-13997 (2005).

39 Menon KK, Piddlesden SJ, Bernard CC. Demyelinating antibodies to myelin oligodendrocyte glycoprotein and galactocerebroside induce degradation of myelin basic protein in isolated human myelin. J. Neurochem. 69(1), 214-222 (1997).

40 Kinzel S, Lehmann-Horn K, Torke $\mathrm{S}$ et al. Myelin-reactive antibodies initiate T cell-mediated CNS autoimmune disease by opsonization of endogenous antigen. Acta Neuropathol. 132(1), 43-58 (2016).

41 Flach AC, Litke T, Strauss J et al. Autoantibody-boosted T-cell reactivation in the target organ triggers manifestation of autoimmune CNS disease. Proc. Natl Acad. Sci. USA 113(12), 3323-3328 (2016).

42 Storch MK, Piddlesden S, Haltia M, livanainen M, Morgan P, Lassmann H. Multiple sclerosis: in situ evidence for antibody- and complement-mediated demyelination. Ann. Neurol. 43(4), 465-471 (1998). 
43 Hundgeburth LC, Wunsch M, Rovituso D et al. The complement system contributes to the pathology of experimental autoimmune encephalomyelitis by triggering demyelination and modifying the antigen-specific $\mathrm{T}$ and $\mathrm{B}$ cell response. Clin. Immunol. 146(3), 155-164 (2013).

44 Terenyi N, Nagy N, Papp K, Prechl J, Olah I, Erdei A. Transient decomplementation of mice delays onset of experimental autoimmune encephalomyelitis and impairs MOG-specific T cell response and autoantibody production. Mol. Immunol. 47(1), 57-63 (2009).

45 Barr TA, Shen P, Brown S et al. B cell depletion therapy ameliorates autoimmune disease through ablation of IL-6-producing B cells. J. Exp. Med. 209(5), 1001-1010 (2012).

46 Jagessar SA, Heijmans N, Oh L et al. Antibodies against human BLyS and APRIL attenuate EAE development in marmoset monkeys. J. Neuroimmune Pharmacol. 7(3), 557-570 (2012).

47 Vincent FB, Saulep-Easton D, Figgett WA, Fairfax KA, Mackay F. The BAFF/APRIL system: emerging functions beyond B cell biology and autoimmunity. Cytokine Growth Factor Rev. 24(3), 203-215 (2013).

48 Magliozzi R, Columba-Cabezas S, Serafini B, Aloisi F. Intracerebral expression of CXCL13 and BAFF is accompanied by formation of lymphoid follicle-like structures in the meninges of mice with relapsing experimental autoimmune encephalomyelitis. $J$. Neuroimmunol. 148(1-2), 11-23 (2004).

49 Wootla B, Denic A, Watzlawik JO, Warrington AE, Rodriguez M. Antibody-mediated oligodendrocyte remyelination promotes axon health in progressive demyelinating disease. Mol. Neurobiol. 53(8), 5217-5228 (2016).

50 Ciric B, Howe CL, Paz Soldan M et al. Human monoclonal IgM antibody promotes CNS myelin repair independent of $\mathrm{Fc}$ function. Brain Pathol. 13(4), 608-616 (2003).

51 Duddy ME, Alter A, Bar-Or A. Distinct profiles of human B cell effector cytokines: a role in immune regulation? J. Immunol. 172(6), 3422-3427 (2004).

52 Correale J, Fiol M, Gilmore W. The risk of relapses in multiple sclerosis during systemic infections. Neurology 67(4), 652-659 (2006).

53 Vukusic S, Hutchinson M, Hours $\mathrm{M}$ et al. Pregnancy and multiple sclerosis (the PRIMS study): clinical predictors of post-partum relapse. Brain 127(Pt 6), 1353-1360 (2004).

54 Laroni A, Armentani E, Kerlero De Rosbo N et al. Dysregulation of regulatory CD56(bright) NK cells/T cells interactions in multiple sclerosis. J. Autoimmun. 72, 8-18 (2016).

55 Trapp BD, Stys PK. Virtual hypoxia and chronic necrosis of demyelinated axons in multiple sclerosis. Lancet Neurol. 8(3), 280-291 (2009).

-. This highly informative article describes virtual hypoxia and neurodegeneration in the context of multiple sclerosis (MS).

56 Jeffery ND, Crang AJ, O'leary MT, Hodge SJ, Blakemore WF. Behavioural consequences of oligodendrocyte progenitor cell transplantation into experimental demyelinating lesions in the rat spinal cord. Eur. J. Neurosci. 11(5), 1508-1514 (1999).

57 Lampron A, Larochelle A, Laflamme $\mathrm{N}$ et al. Inefficient clearance of myelin debris by microglia impairs remyelinating processes. J. Exp. Med. 212(4), 481-495 (2015).

58 Kotter MR, Li WW, Zhao C, Franklin RJ. Myelin impairs CNS remyelination by inhibiting oligodendrocyte precursor cell differentiation. J. Neurosci. 26(1), 328-332 (2006).

59 Sosa RA, Murphey C, Robinson RR, Forsthuber TG. IFN-gamma ameliorates autoimmune encephalomyelitis by limiting myelin lipid peroxidation. Proc. Natl Acad. Sci. USA 112(36), E5038-5047 (2015).

60 Wujek JR, Bjartmar C, Richer E et al. Axon loss in the spinal cord determines permanent neurological disability in an animal model of multiple sclerosis. J. Neuropathol. Exp. Neurol. 61(1), 23-32 (2002).

61 Prineas JW, Kwon EE, Cho ES et al. Immunopathology of secondary-progressive multiple sclerosis. Ann. Neurol. 50(5), 646-657 (2001). Reich DS, Lucchinetti CF, Calabresi PA. Multiple sclerosis. N. Engl. J. Med. 378(2), 169-180 (2018)

Trapp BD, Peterson J, Ransohoff RM, Rudick R, Mork S, Bo L. Axonal transection in the lesions of multiple sclerosis. N. Engl. J. Med. 338(5), 278-285 (1998).

Dang AK, Tesfagiorgis Y, Jain RW, Craig HC, Kerfoot SM. Meningeal Infiltration of the Spinal Cord by Non-Classically Activated B Cells is Associated with Chronic Disease Course in a Spontaneous B Cell-Dependent Model of CNS Autoimmune Disease. Front Immunol. 6, 470 (2015).

Van Waesberghe JH, Kamphorst W, De Groot CJ et al. Axonal loss in multiple sclerosis lesions: magnetic resonance imaging insights into substrates of disability. Ann. Neurol. 46(5), 747-754 (1999).

67 Mews I, Bergmann M, Bunkowski S, Gullotta F, Bruck W. Oligodendrocyte and axon pathology in clinically silent multiple sclerosis lesions. Mult. Scler. 4(2), 55-62 (1998).

69 Raps SP, Lai JC, Hertz L, Cooper AJ. GSH is present in high concentrations in cultured astrocytes but not in cultured neurons. Brain Res. 493(2), 398-401 (1989). 
70 Lucius R, Sievers J. Postnatal retinal ganglion cells in vitro: protection against reactive oxygen species (ROS)-induced axonal degeneration by cocultured astrocytes. Brain Res. 743(1-2), 56-62 (1996).

71 Schurr A, Payne RS, Miller JJ, Rigor BM. Brain lactate, not glucose, fuels the recovery of synaptic function from hypoxia upon reoxygenation: an in vitro study. Brain Res. 744(1), 105-111 (1997).

72 Bouzier AK, Thiaudiere E, Biran M, Rouland R, Canioni P, Merle M. The metabolism of [3-(13)C]lactate in the rat brain is specific of a pyruvate carboxylase-deprived compartment. J. Neurochem. 75(2), 480-486 (2000).

$73 \mathrm{Qu} \mathrm{H}$, Haberg A, Haraldseth O, Unsgard G, Sonnewald U. (13)C MR spectroscopy study of lactate as substrate for rat brain. Dev. Neurosci. 22(5-6), 429-436 (2000).

74 Serres S, Bezancon E, Franconi JM, Merle M. Ex vivo NMR study of lactate metabolism in rat brain under various depressed states. J. Neurosci. Res. 79(1-2), 19-25 (2005).

75 Itoh Y, Esaki T, Shimoji K et al. Dichloroacetate effects on glucose and lactate oxidation by neurons and astroglia in vitro and on glucose utilization by brain in vivo. Proc. Natl Acad. Sci. USA 100(8), 4879-4884 (2003).

76 Bouzier-Sore AK, Voisin P, Bouchaud V, Bezancon E, Franconi JM, Pellerin L. Competition between glucose and lactate as oxidative energy substrates in both neurons and astrocytes: a comparative NMR study. Eur. J. Neurosci. 24(6), 1687-1694 (2006).

77 Herrero-Mendez A, Almeida A, Fernandez E, Maestre C, Moncada S, Bolanos JP. The bioenergetic and antioxidant status of neurons is controlled by continuous degradation of a key glycolytic enzyme by APC/C-Cdh1. Nat. Cell Biol. 11(6), 747-752 (2009).

78 Dringen R, Hirrlinger J. Glutathione pathways in the brain. Biol. Chem. 384(4), 505-516 (2003).

79 Maher F, Davies-Hill TM, Lysko PG, Henneberry RC, Simpson IA. Expression of two glucose transporters, GLUT1 and GLUT3, in cultured cerebellar neurons: Evidence for neuron-specific expression of GLUT3. Mol. Cell. Neurosci. 2(4), 351-360 (1991).

80 Jain A, Martensson J, Stole E, Auld PA, Meister A. Glutathione deficiency leads to mitochondrial damage in brain. Proc. Natl Acad. Sci. USA 88(5), 1913-1917 (1991).

81 Haworth RA, Hunter DR. The Ca2+-induced membrane transition in mitochondria. II. Nature of the Ca2+ trigger site. Arch. Biochem. Biophys. 195(2), 460-467 (1979).

82 Pellerin L, Magistretti PJ. Glutamate uptake into astrocytes stimulates aerobic glycolysis: a mechanism coupling neuronal activity to glucose utilization. Proc. Natl Acad. Sci. USA 91(22), 10625-10629 (1994).

- Provides evidence for metabolic coupling and the neuron-astrocyte lactate shuttle.

83 Magistretti PJ. Neuron-glia metabolic coupling and plasticity. J. Exp. Biol. 209(Pt 12), 2304-2311 (2006).

84 Magistretti PJ, Morrison JH, Shoemaker WJ, Sapin V, Bloom FE. Vasoactive intestinal polypeptide induces glycogenolysis in mouse cortical slices: a possible regulatory mechanism for the local control of energy metabolism. Proc. Natl Acad. Sci. USA 78(10), 6535-6539 (1981).

85 Park LC, Zhang H, Gibson GE. Co-culture with astrocytes or microglia protects metabolically impaired neurons. Mech. Ageing Dev. 123(1), 21-27 (2001).

86 Tsacopoulos M, Poitry-Yamate CL, Poitry S, Perrottet P, Veuthey AL. The nutritive function of glia is regulated by signals released by neurons. Glia 21(1), 84-91 (1997).

87 Magistretti PJ, Pellerin L, Rothman DL, Shulman RG. Energy on demand. Science 283(5401), 496-497 (1999).

88 Sontheimer H, Fernandez-Marques E, Ullrich N, Pappas CA, Waxman SG. Astrocyte Na+ channels are required for maintenance of $\mathrm{Na}+/ \mathrm{K}(+)$-ATPase activity. J. Neurosci. $14(5$ Pt 1), 2464-2475 (1994).

89 Wullner U, Seyfried J, Groscurth P et al. Glutathione depletion and neuronal cell death: the role of reactive oxygen intermediates and mitochondrial function. Brain Res. 826(1), 53-62 (1999).

90 Bellomo G, Mirabelli F, Dimonte D et al. Formation and reduction of glutathione-protein mixed disulfides during oxidative stress. A study with isolated hepatocytes and menadione (2-methyl-1,4-naphthoquinone). Biochem. Pharmacol. 36(8), 1313-1320 (1987).

91 Bolanos JP, Almeida A, Moncada S. Glycolysis: a bioenergetic or a survival pathway? Trends Biochem. Sci. 35(3), 145-149 (2010).

92 Lu SC. Glutathione synthesis. Biochim. Biophys. Acta 1830(5), 3143-3153 (2013).

93 Makar TK, Nedergaard M, Preuss A, Gelbard AS, Perumal AS, Cooper AJ. Vitamin E, ascorbate, glutathione, glutathione disulfide, and enzymes of glutathione metabolism in cultures of chick astrocytes and neurons: evidence that astrocytes play an important role in antioxidative processes in the brain. J. Neurochem. 62(1), 45-53 (1994).

94 Minich T, Riemer J, Schulz JB, Wielinga P, Wijnholds J, Dringen R. The multidrug resistance protein 1 (Mrp1), but not Mrp5, mediates export of glutathione and glutathione disulfide from brain astrocytes. J. Neurochem. 97(2), 373-384 (2006).

95 Wang XF, Cynader MS. Astrocytes provide cysteine to neurons by releasing glutathione. J. Neurochem. 74(4), 1434-1442 (2000).

96 Aoyama K, Suh SW, Hamby AM et al. Neuronal glutathione deficiency and age-dependent neurodegeneration in the EAAC1 deficient mouse. Nat Neurosci. 9(1), 119-126 (2006).

97 Iadecola C, Nedergaard M. Glial regulation of the cerebral microvasculature. Nat. Neurosci. 10(11), 1369-1376 (2007).

98 Warburg O. On respiratory impairment in cancer cells. Science 124(3215), 269-270 (1956). 
99 Pierre K, Pellerin L. Monocarboxylate transporters in the central nervous system: distribution, regulation and function. J. Neurochem. 94(1), 1-14 (2005).

100 Sotelo-Hitschfeld T, Niemeyer MI, Machler P et al. Channel-mediated lactate release by K(+)-stimulated astrocytes. J. Neurosci. 35(10), 4168-4178 (2015).

101 Karagiannis A, Sylantyev S, Hadjihambi A, Hosford PS, Kasparov S, Gourine AV. Hemichannel-mediated release of lactate. J. Cereb. Blood Flow Metab. 36(7), 1202-1211 (2016).

102 Lovatt D, Sonnewald U, Waagepetersen HS et al. The transcriptome and metabolic gene signature of protoplasmic astrocytes in the adult murine cortex. J. Neurosci. 27(45), 12255-12266 (2007).

103 Budd SL, Nicholls DG. Mitochondria, calcium regulation, and acute glutamate excitotoxicity in cultured cerebellar granule cells. $J$. Neurochem. 67(6), 2282-2291 (1996).

104 Shashidharan P, Huntley GW, Meyer T, Morrison JH, Plaitakis A. Neuron-specific human glutamate transporter: molecular cloning, characterization and expression in human brain. Brain Res. 662(1-2), 245-250 (1994).

105 Shashidharan P, Plaitakis A. Cloning and characterization of a glutamate transporter cDNA from human cerebellum. Biochim. Biophys. Acta 1216(1), 161-164 (1993).

106 Rosenberg PA, Aizenman E. Hundred-fold increase in neuronal vulnerability to glutamate toxicity in astrocyte-poor cultures of rat cerebral cortex. Neurosci. Lett. 103(2), 162-168 (1989).

107 Fernandez-Fernandez S, Almeida A, Bolanos JP. Antioxidant and bioenergetic coupling between neurons and astrocytes. Biochem. J. 443(1), 3-11 (2012).

108 Funfschilling U, Supplie LM, Mahad D et al. Glycolytic oligodendrocytes maintain myelin and long-term axonal integrity. Nature 485(7399), 517-521 (2012).

109 Lappe-Siefke C, Goebbels S, Gravel M et al. Disruption of Cnp1 uncouples oligodendroglial functions in axonal support and myelination. Nat. Genet. 33(3), 366-374 (2003).

110 Lee Y, Morrison BM, Li Y et al. Oligodendroglia metabolically support axons and contribute to neurodegeneration. Nature 487(7408), 443-448 (2012).

111 Juurlink BH, Thorburne SK, Hertz L. Peroxide-scavenging deficit underlies oligodendrocyte susceptibility to oxidative stress. Glia 22(4), 371-378 (1998).

112 Back SA, Gan X, Li Y, Rosenberg PA, Volpe JJ. Maturation-dependent vulnerability of oligodendrocytes to oxidative stress-induced death caused by glutathione depletion. J. Neurosci. 18(16), 6241-6253 (1998).

113 Rinholm JE, Hamilton NB, Kessaris N, Richardson WD, Bergersen LH, Attwell D. Regulation of oligodendrocyte development and myelination by glucose and lactate. J. Neurosci. 31(2), 538-548 (2011).

114 Pitt D, Nagelmeier IE, Wilson HC, Raine CS. Glutamate uptake by oligodendrocytes: Implications for excitotoxicity in multiple sclerosis. Neurology 61(8), 1113-1120 (2003).

115 Deng W, Yue Q, Rosenberg PA, Volpe JJ, Jensen FE. Oligodendrocyte excitotoxicity determined by local glutamate accumulation and mitochondrial function. J. Neurochem. 98(1), 213-222 (2006).

116 Stampfli R. Saltatory conduction in nerve. Physiol. Rev. 34(1), 101-112 (1954).

117 Griffiths I, Klugmann M, Anderson T et al. Axonal swellings and degeneration in mice lacking the major proteolipid of myelin. Science 280(5369), 1610-1613 (1998).

118 Pohl HB, Porcheri C, Mueggler T et al. Genetically induced adult oligodendrocyte cell death is associated with poor myelin clearance, reduced remyelination, and axonal damage. J. Neurosci. 31(3), 1069-1080 (2011).

119 Oluich LJ, Stratton JA, Xing YL et al. Targeted ablation of oligodendrocytes induces axonal pathology independent of overt demyelination. J. Neurosci. 32(24), 8317-8330 (2012).

120 Hirrlinger J, Gutterer JM, Kussmaul L, Hamprecht B, Dringen R. Microglial cells in culture express a prominent glutathione system for the defense against reactive oxygen species. Dev. Neurosci. 22(5-6), 384-392 (2000).

121 Singh V, Gera R, Kushwaha R, Sharma AK, Patnaik S, Ghosh D. Hijacking microglial glutathione by inorganic arsenic impels bystander death of immature neurons through extracellular cystine/glutamate imbalance. Sci. Rep. 6, 30601 (2016).

122 Moreira TJ, Pierre K, Maekawa F et al. Enhanced cerebral expression of MCT1 and MCT2 in a rat ischemia model occurs in activated microglial cells. J. Cereb. Blood Flow Metab. 29(7), 1273-1283 (2009).

123 Mason S, Van Furth AM, Mienie LJ et al. A hypothetical astrocyte-microglia lactate shuttle derived from a (1)H NMR metabolomics analysis of cerebrospinal fluid from a cohort of South African children with tuberculous meningitis. Metabolomics 11(4), 822-837 (2015).

124 Van Landeghem FK, Stover JF, Bechmann I et al. Early expression of glutamate transporter proteins in ramified microglia after controlled cortical impact injury in the rat. Glia 35(3), 167-179 (2001).

125 Chretien F, Vallat-Decouvelaere AV, Bossuet C et al. Expression of excitatory amino acid transporter-2 (EAAT-2) and glutamine synthetase (GS) in brain macrophages and microglia of SIVmac251-infected macaques. Neuropathol. Appl.

Neurobiol. 28(5), 410-417 (2002). 
126 Kato G, Inada H, Wake $\mathrm{H}$ et al. Microglial contact prevents excess depolarization and rescues neurons from excitotoxicity. eNeuro 3(3), (2016).

127 Witte ME, Mahad DJ, Lassmann H, Van Horssen J. Mitochondrial dysfunction contributes to neurodegeneration in multiple sclerosis. Trends Mol. Med. 20(3), 179-187 (2014).

128 Haider L, Fischer MT, Frischer JM et al. Oxidative damage in multiple sclerosis lesions. Brain 134(Pt 7), 1914-1924 (2011).

129 Mahad DJ, Ziabreva I, Campbell G et al. Mitochondrial changes within axons in multiple sclerosis. Brain 132(Pt 5), 1161-1174 (2009).

130 Dutta R, Mcdonough J, Yin X et al. Mitochondrial dysfunction as a cause of axonal degeneration in multiple sclerosis patients. Ann. Neurol. 59(3), 478-489 (2006).

- Provides evidence of calcium-mediated destruction of demyelinated axons in patients with MS.

131 Stys PK, Waxman SG, Ransom BR. Ionic mechanisms of anoxic injury in mammalian CNS white matter: role of $\mathrm{Na}+$ channels and $\mathrm{Na}(+)-\mathrm{Ca} 2+$ exchanger. J. Neurosci. 12(2), 430-439 (1992).

132 Biller A, Pflugmann I, Badde $S$ et al. Sodium MRI in multiple sclerosis is compatible with intracellular sodium accumulation and inflammation-induced hyper-cellularity of acute brain lesions. Sci. Rep. 6, 31269 (2016).

133 Petracca M, Vancea RO, Fleysher L, Jonkman LE, Oesingmann N, Inglese M. Brain intra- and extracellular sodium concentration in multiple sclerosis: a 7 T MRI study. Brain 139(Pt 3), 795-806 (2016).

134 Paling D, Solanky BS, Riemer F et al. Sodium accumulation is associated with disability and a progressive course in multiple sclerosis. Brain 136(Pt 7), 2305-2317 (2013).

135 Bolanos JP, Heales SJ, Land JM, Clark JB. Effect of peroxynitrite on the mitochondrial respiratory chain: differential susceptibility of neurones and astrocytes in primary culture. J. Neurochem. 64(5), 1965-1972 (1995).

136 Clementi E, Brown GC, Feelisch M, Moncada S. Persistent inhibition of cell respiration by nitric oxide: crucial role of S-nitrosylation of mitochondrial complex I and protective action of glutathione. Proc. Natl Acad. Sci. USA 95(13), 7631-7636 (1998).

137 Borutaite V, Budriunaite A, Brown GC. Reversal of nitric oxide-, peroxynitrite- and S-nitrosothiol-induced inhibition of mitochondrial respiration or complex I activity by light and thiols. Biochim. Biophys. Acta 1459(2-3), 405-412 (2000).

138 Liu JS, Zhao ML, Brosnan CF, Lee SC. Expression of inducible nitric oxide synthase and nitrotyrosine in multiple sclerosis lesions. Am. J. Pathol. 158(6), 2057-2066 (2001).

139 Holley JE, Gveric D, Newcombe J, Cuzner ML, Gutowski NJ. Astrocyte characterization in the multiple sclerosis glial scar. Neuropathol. Appl. Neurobiol. 29(5), 434-444 (2003).

140 Goddard DR, Berry M, Butt AM. In vivo actions of fibroblast growth factor-2 and insulin-like growth factor-I on oligodendrocyte development and myelination in the central nervous system. J. Neurosci. Res. 57(1), 74-85 (1999).

141 Lee SC, Dickson DW, Liu W, Brosnan CF. Induction of nitric oxide synthase activity in human astrocytes by interleukin-1 beta and interferon-gamma. J. Neuroimmunol. 46(1-2), 19-24 (1993).

142 Hamby ME, Hewett JA, Hewett SJ. TGF-beta1 potentiates astrocytic nitric oxide production by expanding the population of astrocytes that express NOS-2. Glia 54(6), 566-577 (2006).

143 Fischer MT, Sharma R, Lim JL et al. NADPH oxidase expression in active multiple sclerosis lesions in relation to oxidative tissue damage and mitochondrial injury. Brain 135(Pt 3), 886-899 (2012).

144 Mann CL, Davies MB, Boggild MD et al. Glutathione S-transferase polymorphisms in MS: their relationship to disability. Neurology 54(3), 552-557 (2000).

145 Calabrese V, Scapagnini G, Ravagna A et al. Nitric oxide synthase is present in the cerebrospinal fluid of patients with active multiple sclerosis and is associated with increases in cerebrospinal fluid protein nitrotyrosine and S-nitrosothiols and with changes in glutathione levels. J. Neurosci. Res. 70(4), 580-587 (2002).

146 Calabrese V, Raffaele R, Cosentino E, Rizza V. Changes in cerebrospinal fluid levels of malondialdehyde and glutathione reductase activity in multiple sclerosis. Int. J. Clin. Pharmacol. Res. 14(4), 119-123 (1994).

147 Shih AY, Johnson DA, Wong G et al. Coordinate regulation of glutathione biosynthesis and release by Nrf2-expressing glia potently protects neurons from oxidative stress. J. Neurosci. 23(8), 3394-3406 (2003).

148 Morales Pantoja IE, Hu CL, Perrone-Bizzozero NI, Zheng J, Bizzozero OA. Nrf2-dysregulation correlates with reduced synthesis and low glutathione levels in experimental autoimmune encephalomyelitis. J. Neurochem. 139(4), 640-650 (2016).

149 Licht-Mayer S, Wimmer I, Traffehn S et al. Cell type-specific Nrf2 expression in multiple sclerosis lesions. Acta Neuropathol. 130(2), 263-277 (2015).

150 Nijland PG, Michailidou I, Witte ME et al. Cellular distribution of glucose and monocarboxylate transporters in human brain white matter and multiple sclerosis lesions. Glia 62(7), 1125-1141 (2014).

151 Zeis T, Allaman I, Gentner M et al. Metabolic gene expression changes in astrocytes in Multiple Sclerosis cerebral cortex are indicative of immune-mediated signaling. Brain Behav. Immun. 48, 313-325 (2015).

- Provides evidence of dysregulation in the astrocyte-neruon lactate shuttle and the glutamate-glutamine cycle in brains of patients with MS. 
152 Albanese M, Zagaglia S, Landi D et al. Cerebrospinal fluid lactate is associated with multiple sclerosis disease progression. J. Neuroinflammation 13, 36 (2016).

153 Aasly J, Garseth M, Sonnewald U, Zwart JA, White LR, Unsgard G. Cerebrospinal fluid lactate and glutamine are reduced in multiple sclerosis. Acta Neurol. Scand. 95(1), 9-12 (1997).

154 Werner P, Pitt D, Raine CS. Multiple sclerosis: altered glutamate homeostasis in lesions correlates with oligodendrocyte and axonal damage. Ann. Neurol. 50(2), 169-180 (2001).

155 Koehler NK, Genain CP, Giesser B, Hauser SL. The human T cell response to myelin oligodendrocyte glycoprotein: a multiple sclerosis family-based study. J. Immunol. 168(11), 5920-5927 (2002).

156 Rohowsky-Kochan C, Molinaro D, Cook SD. Cytokine secretion profile of myelin basic protein-specific T cells in multiple sclerosis. Mult. Scler. 6(2), 69-77 (2000).

157 Ohashi T, Yamamura T, Inobe J, Kondo T, Kunishita T, Tabira T. Analysis of proteolipid protein (PLP)-specific T cells in multiple sclerosis: identification of PLP 95-116 as an HLA-DR2,w15-associated determinant. Int. Immunol. 7(11), 1771-1778 (1995).

158 Nikic I, Merkler D, Sorbara C et al. A reversible form of axon damage in experimental autoimmune encephalomyelitis and multiple sclerosis. Nat. Med. 17(4), 495-499 (2011).

159 Black JA, Felts P, Smith KJ, Kocsis JD, Waxman SG. Distribution of sodium channels in chronically demyelinated spinal cord axons: immunoultrastructural localization and electrophysiological observations. . Brain Res. 761(1), 1 (1997).

160 Gray E, Thomas TL, Betmouni S, Scolding N, Love S. Elevated activity and microglial expression of myeloperoxidase in demyelinated cerebral cortex in multiple sclerosis. Brain Pathol. 18(1), 86-95 (2008).

161 Cheret C, Gervais A, Lelli A et al. Neurotoxic activation of microglia is promoted by a nox1-dependent NADPH oxidase. J. Neurosci. 28(46), 12039-12051 (2008).

162 Vercellino M, Merola A, Piacentino C et al. Altered glutamate reuptake in relapsing-remitting and secondary progressive multiple sclerosis cortex: correlation with microglia infiltration, demyelination, and neuronal and synaptic damage. J. Neuropathol. Exp. Neurol. 66(8), 732-739 (2007).

163 Lastres-Becker I, Innamorato NG, Jaworski T et al. Fractalkine activates NRF2/NFE2L2 and heme oxygenase 1 to restrain tauopathy-induced microgliosis. Brain 137(Pt 1), 78-91 (2014).

164 Persson M, Sandberg M, Hansson E, Ronnback L. Microglial glutamate uptake is coupled to glutathione synthesis and glutamate release. Eur. J. Neurosci. 24(4), 1063-1070 (2006).

165 Pampliega O, Domercq M, Soria FN, Villoslada P, Rodriguez-Antiguedad A, Matute C. Increased expression of cystine/glutamate antiporter in multiple sclerosis. J. Neuroinflammation. 8, 63 (2011).

166 Drulovic J, Basic-Kes V, Grgic S et al. The prevalence of pain in adults with multiple sclerosis: a multicenter cross-sectional survey. Pain Med. 16(8), 1597-1602 (2015).

167 Svendsen KB, Jensen TS, Hansen HJ, Bach FW. Sensory function and quality of life in patients with multiple sclerosis and pain. Pain 114(3), 473-481 (2005).

168 Young J, Amatya B, Galea MP, Khan F. Chronic pain in multiple sclerosis: a 10-year longitudinal study. Scand. J. Pain 16, 198-203 (2017).

169 O'connor AB, Schwid SR, Herrmann DN, Markman JD, Dworkin RH. Pain associated with multiple sclerosis: systematic review and proposed classification. Pain 137(1), 96-111 (2008).

170 Seixas D, Foley P, Palace J, Lima D, Ramos I, Tracey I. Pain in multiple sclerosis: a systematic review of neuroimaging studies. Neuroimage Clin. 5, 322-331 (2014).

171 Woolf CJ, Mannion RJ. Neuropathic pain: aetiology, symptoms, mechanisms, and management. Lancet 353(9168), 1959-1964 (1999).

172 Osterberg A, Boivie J, Thuomas KA. Central pain in multiple sclerosis - prevalence and clinical characteristics. Eur. J. Pain 9(5), 531-542 (2005).

173 Wang IC, Chung CY, Liao F, Chen CC, Lee CH. Peripheral sensory neuron injury contributes to neuropathic pain in experimental autoimmune encephalomyelitis. Sci. Rep. 7, 42304 (2017).

174 Olechowski CJ, Truong JJ, Kerr BJ. Neuropathic pain behaviours in a chronic-relapsing model of experimental autoimmune encephalomyelitis (EAE). Pain 141(1-2), 156-164 (2009).

175 Grace PM, Loram LC, Christianson JP et al. Behavioral assessment of neuropathic pain, fatigue, and anxiety in experimental autoimmune encephalomyelitis (EAE) and attenuation by interleukin-10 gene therapy. Brain Behav. Immun. 59, 49-54 (2017).

176 Olechowski CJ, Parmar A, Miller B et al. A diminished response to formalin stimulation reveals a role for the glutamate transporters in the altered pain sensitivity of mice with experimental autoimmune encephalomyelitis (EAE). Pain 149(3), 565-572 (2010).

- Provides evidence of neuopathic pain during experimental autoimmune encephalomyelitis (EAE) and that the abnormal pain response during EAE is associated with dysregulation of glutamate transporter function.

177 Gottesfeld Z, Teitelbaum D, Webb C, Arnon R. Changes in the GABA system in experimental allergic encephalomyelitis-induced paralysis. J. Neurochem. 27(3), 695-699 (1976). 
178 Honegger CG, Krenger W, Langemann H. Changes in amino acid contents in the spinal cord and brainstem of rats with experimental autoimmune encephalomyelitis. J. Neurochem. 53(2), 423-427 (1989).

179 Musgrave T, Benson C, Wong G et al. The MAO inhibitor phenelzine improves functional outcomes in mice with experimental autoimmune encephalomyelitis (EAE). Brain Behav. Immun. 25(8), 1677-1688 (2011).

180 Kan QC, Zhang S, Xu YM, Zhang GX, Zhu L. Matrine regulates glutamate-related excitotoxic factors in experimental autoimmune encephalomyelitis. Neurosci. Lett. 560, 92-97 (2014).

181 Qureshi GA, Baig MS. Quantitation of free amino acids in biological samples by high-performance liquid chromatography. Application of the method in evaluating amino acid levels in cerebrospinal fluid and plasma of patients with multiple sclerosis. $J$. Chromatogr. 459, 237-244 (1988).

182 Manyam NV, Katz L, Hare TA, Gerber JC 3rd, Grossman MH. Levels of gamma-aminobutyric acid in cerebrospinal fluid in various neurologic disorders. Arch. Neurol. 37(6), 352-355 (1980).

183 Lock C, Hermans G, Pedotti R et al. Gene-microarray analysis of multiple sclerosis lesions yields new targets validated in autoimmune encephalomyelitis. Nat. Med. 8(5), 500-508 (2002).

184 Achar VS, Welch KM, Chabi E, Bartosh K, Meyer JS. Cerebrospinal fluid gamma-aminobutyric acid in neurologic disease. Neurology 26(8), 777-780 (1976).

185 Falco A, Pennucci R, Brambilla E, De Curtis I. Reduction in parvalbumin-positive interneurons and inhibitory input in the cortex of mice with experimental autoimmune encephalomyelitis. Exp. Brain Res. 232(7), 2439-2449 (2014).

186 Petitjean H, Pawlowski SA, Fraine SL et al. Dorsal horn parvalbumin neurons are gate-keepers of touch-evoked pain after nerve injury. Cell Rep. 13(6), 1246-1257 (2015).

187 Hewett SJ, Csernansky CA, Choi DW. Selective potentiation of NMDA-induced neuronal injury following induction of astrocytic iNOS. Neuron 13(2), 487-494 (1994).

188 Wang H, Sun H, Della Penna K et al. Chronic neuropathic pain is accompanied by global changes in gene expression and shares pathobiology with neurodegenerative diseases. Neuroscience 114(3), 529-546 (2002).

189 Chiang CY, Wang J, Xie YF et al. Astroglial glutamate-glutamine shuttle is involved in central sensitization of nociceptive neurons in rat medullary dorsal horn. J. Neurosci. 27(34), 9068-9076 (2007).

190 Haas R, Smith J, Rocher-Ros V et al. Lactate regulates metabolic and pro-inflammatory circuits in control of T cell migration and effector functions. PLoS Biol. 13(7), e1002202 (2015).

191 Chenal J, Pierre K, Pellerin L. Insulin and IGF-1 enhance the expression of the neuronal monocarboxylate transporter MCT2 by translational activation via stimulation of the phosphoinositide 3-kinase-Akt-mammalian target of rapamycin pathway. Eur. J. Neurosci. 27(1), 53-65 (2008).

192 Yao DL, Liu X, Hudson LD, Webster HD. Insulin-like growth factor I treatment reduces demyelination and up-regulates gene expression of myelin-related proteins in experimental autoimmune encephalomyelitis. Proc. Natl Acad. Sci. USA 92(13), 6190-6194 (1995).

193 Zhang Y, Qin W, Qian Z et al. Peripheral pain is enhanced by insulin-like growth factor 1 through a G protein-mediated stimulation of T-type calcium channels. Sci. Signal. 7(346), ra94 (2014).

194 Hayashi A, Suzuki H, Itoh K, Yamamoto M, Sugiyama Y. Transcription factor Nrf2 is required for the constitutive and inducible expression of multidrug resistance-associated protein 1 in mouse embryo fibroblasts. Biochem. Biophys. Res. Commun. 310(3), 824-829 (2003).

195 Strassburger-Krogias K, Ellrichmann G, Krogias C, Altmeyer P, Chan A, Gold R. Fumarate treatment in progressive forms of multiple sclerosis: first results of a single-center observational study. Ther. Adv. Neurol. Disord. 7(5), 232-238 (2014).

196 Huang H, Taraboletti A, Shriver LP. Dimethyl fumarate modulates antioxidant and lipid metabolism in oligodendrocytes. Redox Biol. 5, 169-175 (2015).

197 Kim H, Thompson J, Ji G, Ganapathy V, Neugebauer V. Monomethyl fumarate inhibits pain behaviors and amygdala activity in a rat arthritis model. Pain 158(12), 2376-2385 (2017).

198 Mao P, Manczak M, Shirendeb UP, Reddy PH. MitoQ, a mitochondria-targeted antioxidant, delays disease progression and alleviates pathogenesis in an experimental autoimmune encephalomyelitis mouse model of multiple sclerosis. Biochim. Biophys. Acta 1832(12), 2322-2331 (2013).

199 Davies AL, Desai RA, Bloomfield PS et al. Neurological deficits caused by tissue hypoxia in neuroinflammatory disease. Ann. Neurol. 74(6), 815-825 (2013).

200 Lehmann D, Karussis D, Misrachi-Koll R, Shezen E, Ovadia H, Abramsky O. Oral administration of the oxidant-scavenger $\mathrm{N}$-acetyl-L-cysteine inhibits acute experimental autoimmune encephalomyelitis. J. Neuroimmunol. 50(1), 35-42 (1994).

201 Olechowski CJ, Tenorio G, Sauve Y, Kerr BJ. Changes in nociceptive sensitivity and object recognition in experimental autoimmune encephalomyelitis (EAE). Exp. Neurol. 241, 113-121 (2013).

202 Melzer N, Meuth SG, Torres-Salazar D et al. A beta-lactam antibiotic dampens excitotoxic inflammatory CNS damage in a mouse model of multiple sclerosis. PLoS One 3(9), e3149 (2008). 
203 Basso AS, Frenkel D, Quintana FJ et al. Reversal of axonal loss and disability in a mouse model of progressive multiple sclerosis. J. Clin. Invest. 118(4), 1532-1543 (2008).

204 Bolton C, Paul C. MK-801 limits neurovascular dysfunction during experimental allergic encephalomyelitis. J. Pharmacol. Exp. Ther. 282(1), 397-402 (1997).

205 Wallstrom E, Diener P, Ljungdahl A, Khademi M, Nilsson CG, Olsson T. Memantine abrogates neurological deficits, but not CNS inflammation, in Lewis rat experimental autoimmune encephalomyelitis. J. Neurol. Sci. 137(2), 89-96 (1996).

206 Villoslada P, Arrondo G, Sepulcre J, Alegre M, Artieda J. Memantine induces reversible neurologic impairment in patients with MS. Neurology 72(19), 1630-1633 (2009).

207 Krupp LB, Coyle PK, Doscher C et al. Fatigue therapy in multiple sclerosis: results of a double-blind, randomized, parallel trial of amantadine, pemoline, and placebo. Neurology 45(11), 1956-1961 (1995).

208 Doolen S, Iannitti T, Donahue RR, Shaw BC, Grachen CM, Taylor BK. Fingolimod reduces neuropathic pain behaviors in a mouse model of multiple sclerosis by a sphingosine-1 phosphate receptor 1-dependent inhibition of central sensitization in the dorsal horn. Pain 159(2), 224-238 (2018).

209 Rothhammer V, Kenison JE, Tjon E et al. Sphingosine 1-phosphate receptor modulation suppresses pathogenic astrocyte activation and chronic progressive CNS inflammation. Proc. Natl Acad. Sci. USA 114(8), 2012-2017 (2017).

210 Lublin F, Miller DH, Freedman MS et al. Oral fingolimod in primary progressive multiple sclerosis (INFORMS): a Phase 3, randomised, double-blind, placebo-controlled trial. Lancet 387(10023), 1075-1084 (2016).

211 Kappos L, Radue EW, O'connor P et al. A placebo-controlled trial of oral fingolimod in relapsing multiple sclerosis. N. Engl. J. Med. 362(5), 387-401 (2010).

212 Plemel JR, Liu WQ, Yong VW. Remyelination therapies: a new direction and challenge in multiple sclerosis. Nat. Rev. Drug Discov. 16(9), 617-634 (2017).

213 Lo AC, Saab CY, Black JA, Waxman SG. Phenytoin protects spinal cord axons and preserves axonal conduction and neurological function in a model of neuroinflammation in vivo. J. Neurophysiol. 90(5), 3566-3571 (2003).

214 Bechtold DA, Kapoor R, Smith KJ. Axonal protection using flecainide in experimental autoimmune encephalomyelitis. Ann. Neurol. 55(5), 607-616 (2004).

215 Bechtold DA, Miller SJ, Dawson AC et al. Axonal protection achieved in a model of multiple sclerosis using lamotrigine. J. Neurol. 253(12), 1542-1551 (2006).

216 Schapiro RT. Managing symptoms of multiple sclerosis. Neurol. Clin. 23(1), 177-187, vii (2005).

217 Kapoor R, Furby J, Hayton T et al. Lamotrigine for neuroprotection in secondary progressive multiple sclerosis: a randomised, double-blind, placebo-controlled, parallel-group trial. Lancet Neurol. 9(7), 681-688 (2010).

218 Khan OA. Gabapentin relieves trigeminal neuralgia in multiple sclerosis patients. Neurology 51(2), 611-614 (1998).

219 Frank JA, Richert N, Lewis B et al. A pilot study of recombinant insulin-like growth factor-1 in seven multiple sderosis patients. Mult. Scler. 8(1), 24-29 (2002). 